\title{
Colopexia incisional por celiotomia ou transparietal auxiliada por laparoscopia em cães
}

\author{
Open or laparoscopic assisted transparietal colopexy in dogs
}

\author{
Maurício Veloso Brun ${ }^{1}$ Ney Luis Pippi ${ }^{2}$ Carlos Afonso de Castro Beck ${ }^{3}$ Emerson Antônio Contesini ${ }^{4}$ \\ Rosecler Alves Pereira ${ }^{5}$ Rafael Stedile $^{6}$ Adamas Tassinari Bonfada ${ }^{7}$ Lucas Marques Columé $^{6}$ \\ Kleber Gomes ${ }^{7}$ Antônio Roberto Pinheiro Vieira Junior ${ }^{6}$ Thiago Félix da Silva $^{6}$
}

\section{RESUMO}

Com a finalidade de desenvolver a técnica de colopexia transparietal auxiliada por laparoscopia e comparar seus resultados com os da incisional por celiotomia, foram utilizados 24 cães separados em dois grupos, denominados GA e GL. No GA, constituído de oito animais, foram realizadas colopexias incisionais por celiotomia. No GL, realizaram-se colopexias transparietais auxiliadas por laparoscopia. Os cães do GL foram separados em quatro subgrupos $\left(S_{1}, S_{2}, S_{3}, S_{4}\right)$ com quatro animais cada, sendo utilizado um material diferente para o apoio externo das suturas para cada subgrupo, a citar: equipo de infusão $\left(S_{1}\right)$, disco plástico a partir de frasco de Solução de $\mathrm{NaCl}\left(\mathrm{S}_{2}\right)$, disco confeccionado em borracha de câmara de pneu $\left(S_{3}\right)$ e disco construído com tubo de silicone $\left(S^{4}\right)$. Aos 14 e aos 28 dias de pós-operatório, realizaram-se novos procedimentos laparoscópicos para avaliação das colopexias e coleta das biópsias. O tempo necessário para a realização das cirurgias foi significativamente maior no $G L(p=0,02)$. Em sete cães do $G A$, constatou-se a manutenção da colopexia, sendo que todos apresentavam aderência do omento na região da sutura abdominal. Já em três animais do GL, todos do $S_{4}$, as colopexias não foram mantidas. Na totalidade dos cães desse grupo, foram observadas dermatites elou celulites, sendo os melhores resultados obtidos no $S_{3}$. As principais observações nos exames histológicos aos 14 dias nos animais do GL se referem a maior deposição de tecido conjuntivo no local de aderência do cólon e infiltração deste na musculatura esquelética associada. Já aos 28 dias, não se constataram diferenças entre os grupos. Em ambas as situações, as fibras de colágeno apresentavam-se maturas.
Conclui-se que a técnica auxiliada por laparoscopia é viável; contudo, está associada à ocorrência de lesões teciduais no local de contato com os materiais de apoio para a sutura. Entre estes, o disco de borracha é o que demonstra melhores resultados.

Palavras-chave: cirurgia endoscópica, cirurgia auxiliada por laparoscopia, caninos.

\section{ABSTRACT}

Two groups of dogs, $G A(n=8)$ and $G L(n=16)$ were used to compare the conventional and the transparietal laparsocopic assisted technique for colopexy and to compare with the conventional surgery. In the GA group, the colopexy was proceded by incisional technique trough celiotomy. In the GL group, the colopexy was performed using the transparietal laparoscopic assisted technique. The GL dogs were separated in four subgroups $\left(S_{1}, S_{2}, S_{3}\right.$ and $\left.S_{4}\right)$ with four dogs each. In each subgroup a different stent was used, capton of infusion tube $\left(S_{1}\right)$; plastic disks made with $\mathrm{NaCl}$ solutions bottles $\left(\mathrm{S}_{2}\right)$; disks made with rubber $\left(S_{3}\right)$ and silicone disks $\left(S_{4}\right)$. The time for complete surgery was statically higher in the GL group than GA. Seven $G A$ dogs maintained the colopexy and all of these presented adherences of the omentum in the suture zone. In three GL animals, all of the $S_{4}$ subgroup the colopexies were not maintained. In all dogs of this subgroup dermatitis and/or cellulites were observed. Best results were obtained in the $S_{3}$ subgroup dogs. The main histological observations in the 14d-after surgery biopsies in $G L$ animals were related to a higher connective tissue deposition at the colon adherence, and infiltration of this type of tissue into

\footnotetext{
${ }^{1}$ Médico Veterinário, Mestre, Doutor, Professor da Faculdade de Agronomia e Medicina Veterinária da Universidade de Passo Fundo (FAMV), Universidade de Passo Fundo (UPF). Endereço: FAMV-UPF, Hospital Veterinário, Campus I, Bairro São José, BR 285, km 171, CP 611/631, 99001-970, Passo Fundo, RS. E-mail: mbrun@upf.tche.br

${ }^{2}$ Médico Veterinário, Mestre; PhD, Professor, Programa de Pós-graduação em Medicina Veterinária (PPGMV), Universidade Federal de Santa Maria (UFSM).

${ }^{3}$ Médico Veterinário, Mestre, Doutor, Professor, Faculdade de Medicina Veterinária da Universidade Federal do Rio Grande do Sul (UFRGS). ${ }^{4}$ Médico Veterinário, Mestre, Doutor, Professor, Faculdade de Medicina Veterinária da UFRGS, Aluno do PPG em Medicina Veterinária da UFSM.

${ }_{5}^{5}$ Médico Veterinário, Mestre, Aluna do PPG em Ciências Veterinárias da UFRGS, Professora da FAMV, UPF.

${ }^{6}$ Médico Veterinário autônomo.

${ }^{7}$ Médico Veterinário, Aluno do PPGMV, em Medicina Veterinária da UFSM.
} 
the associated musculature. In the 28d biopsies, no difference was found between groups. In both groups, the collagen fibers presented mature aspect. Concluding, the transparietal laparoscopic assisted technique is viable, however it's associated with tissue lesions in the regions in contact with the material used to support the suture. The rubber disk presented better results.

Key words: endoscopic surgery, laparoscopic assisted surgery, canine.

\section{INTRODUÇÃO}

A colopexia é realizada com o intuito de criar aderências permanentes entre as superfícies serosas do cólon e a parede abdominal, a fim de se evitarem deslocamentos caudais desse órgão (FOSSUM et al., 2002). Seu principal emprego na medicina de pequenos animais consiste no tratamento de prolapsos retais recidivos e não responsivos à sutura de retenção em bolsa de tabaco, que é, também, utilizada em casos de difícil redução manual do tecido protruso (MATTHIESEN \& MARRETTA, 1993). Apesar de existirem diferentes técnicas de colopexia para cães, envolvendo a sutura de fixação com ou sem escarificação dos tecidos relacionados (BURROWS \& ELLISON, 1992; ENGEN, 1986) ou até mesmo com a produção de incisões (POPOVITCH et al., 1994; FOSSUM et al., 2002), a literatura Médica Veterinária dispõe de poucos estudos comparando-as (POPOVITCH et al., 1994). Alguns autores afirmam que os métodos incisionais e não incisionais são igualmente efetivos para produção de aderências cirúrgicas do cólon (FOSSUM et al., 2002), enquanto outros acreditam que os primeiros demonstram melhores resultados (POPOVITCH et al., 1994).

Em humanos, a colopexia está indicada para o tratamento de vólvulo de cólon sigmóide (WELCH \& ANDERSON, 1987), e uma das modalidades cirúrgicas mais comumente empregadas em casos mais complicados de prolapso retal é a retopexia (STEVENSON etal., 1998).Com o advento da cirurgia de mínima invasão, este procedimento também passou a ser realizado pelo método laparoscópico, sendo inicialmente relatado por BERMAN (1992).

Verificando que, na cirurgia de pequenos animais, são poucos os relatos envolvendo colopexia laparoscópica (THOMPSON \& HENDRICKSON, 1998; FREEMAN, 1998; BRUN et al., 2000), em contraponto à importância desse procedimento pelo método convencional, e ainda que esses apresentam grande variação técnica, os autores do presente trabalho objetivaram desenvolver a técnica de colopexia transparietal auxiliada por laparoscopia e comparar seus resultados com os obtidos por meio da operação incisional por celiotomia previamente descrita (POPOVITCH et al., 1994; FOSSUM et al., 2002).

\section{MATERIAL E MÉTODOS}

Foram utilizados 24 cães, sem raça definida, separados em dois grupos (GA e GL), sendo o GA constituído de oito animais, cinco machos e três fêmeas, com peso médio de $14,9 \pm 5,7 \mathrm{~kg}$. O GL constava de 16 cães, oito de cada sexo, com peso médio de $14,4 \pm 5,4 \mathrm{~kg}$. Como procedimentos cirúrgicos foram realizadas colopexias incisionais por celiotomia (GA) e colopexias transparietais auxiliadas por laparoscopia (GL). O GL foi ainda subdividido em quatro subgrupos $\left(\mathrm{S}_{1}, \mathrm{~S}_{2}, \mathrm{~S}_{3}, \mathrm{~S}_{4}\right)$, com quatro animais cada, de acordo com os materiais empregados para o apoio da sutura transparietal. No $S_{1}$, testaram-se segmentos de equipo de infusão; no $\mathrm{S}_{2}$, disco plástico criado a partir de frasco de solução de $\mathrm{NaCl}^{\mathrm{a}}$; no $\mathrm{S}_{3}$, disco confeccionado em borracha de câmara de pneu; e, no $\mathrm{S}_{4}$, disco construído com tubo de silicone $\mathrm{e}^{\mathrm{b}}$.

Em ambos os grupos, os animais foram prémedicados com associação de maleato de acepromazina $\left(0,1 \mathrm{mg} \mathrm{kg}^{-1}\right)$ e citrato de fentanila $\left(5 \mu \mathrm{g} \mathrm{kg}^{-1}\right)$, via intramuscular. Decorridos $15 \mathrm{~min}$, realizou-se a indução anestésica com tiopental sódico $\left(10 \mathrm{mg} \mathrm{kg}^{-1}\right)$. A manutenção foi obtida com halotano em $\mathrm{O}_{2}$ a $100 \%$, administrado em circuito semifechado, por meio de vaporizador universal. Trinta minutos antes do procedimento, aplicou-se ampicilina sódica $\left(30 \mathrm{mg} \mathrm{kg}^{-}\right.$ $\left.{ }^{1}\right)$ via intravenosa. Durante todo o período transoperatório, administrou-se citrato de fentanila a cada 45min, na dose e na via previamente descritas.

Para as colopexias incisionais, os cães foram mantidos em decúbito dorsal e submetidos a incisão pré-púbica na linha média ventral, de aproximadamente $10 \mathrm{~cm}$. Com o auxílio de marcador plástico confeccionado a partir de capa de agulha $18 \times 7 \mathrm{~mm}$, procedeu-se a incisão no cólon de $2,5 \mathrm{~cm}$, abrangendo as camadas serosa, muscular e submucosa. Incisão de comprimento semelhante foi realizada na parede abdominal lateral esquerda, paralelamente ao músculo reto abdominal, envolvendo o peritônio e o músculo transverso abdominal. As bordas laterais das feridas provocadas no cólon e na parede abdominal foram aposicionadas com fio de polipropileno 3-0 , em padrão contínuo simples. Na sequiência, realizouse a aposição das bordas mediais de maneira semelhante. Procedeu-se então a oclusão da cavidade com sutura contínua simples, abrangendo o folheto externo do reto abdominal. O tecido subcutâneo e a pele foram suturados em padrões contínuo e isolado, respectivamente. $\mathrm{O}$ fio utilizado em todas as camadas foi o náilon monofilamentar $2-0^{\mathrm{d}}$.

Para as colopexias auxiliadas por laparoscopia (Figura 1), os cães foram mantidos em 

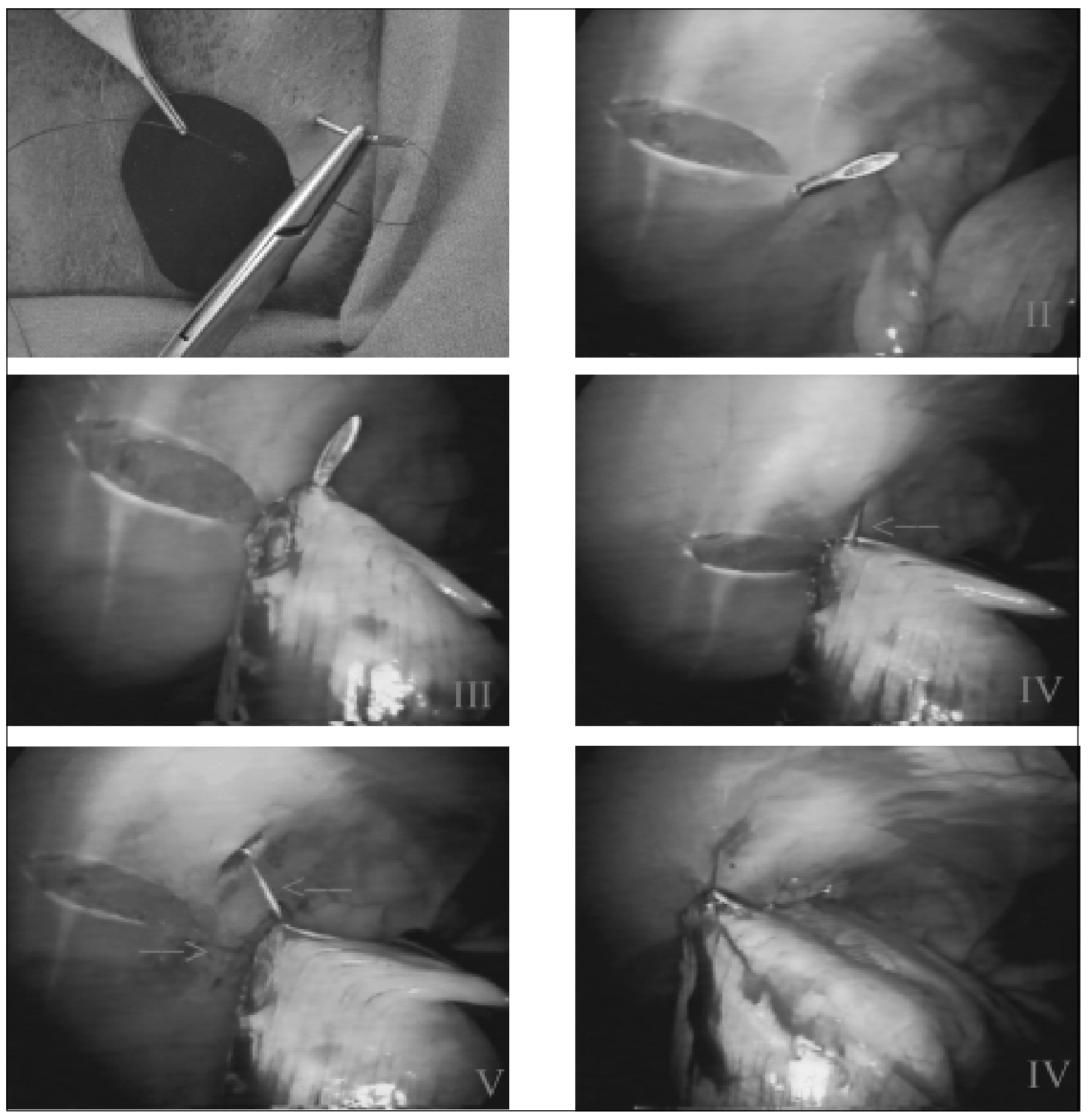

Figura 1 - Procedimento de colopexia transparietal auxiliada por laparoscopia. I) Passagem do fio pelo material de apoio para a sutura transparietal, e aplicação do primeiro ponto através da parede abdominal lateral. II) Visibilização endoscópica da extremidade da agulha utilizada na sutura transparietal. Esta foi introduzida lateralmente à ferida provocada no peritônio e na fáscia transversa. III) Passagem da agulha através da parede do cólon. IV) Passagem da agulha (seta) medialmente à ferida provocada na parede abdominal lateral. V) Fio do primeiro ponto para colopexia transparietal (setas). O mesmo foi reparado externamente à cavidade peitoneal. VI) Aspecto da colopexia após a aplicação das quatro suturas transparietais.

decúbito dorsal e submetidos à incisão de aproximadamente $1,5 \mathrm{~cm}$ na linha média ventral, caudalmente à cicatriz umbilical. Com o auxílio de duas pinças de Backhaus, posicionadas paralelamente à ferida operatória, realizou-se o tracionamento da parede abdominal e à introdução da agulha de Veress ${ }^{\mathrm{e}}$, em ângulo de $90^{\circ}$ em relação à linha alba. A cavidade peritoneal foi insuflada com $\mathrm{CO}_{2}$ a $5 \%$, na velocidade de $21 \mathrm{~min}^{-1}$, até atingir a pressão de $12 \mathrm{mmHg}$. Realizaram-se então a remoção da agulha e, no mesmo 
local, a introdução de trocarte permanente de $10 \mathrm{~mm}^{\mathrm{f}}$, que serviu de conduto para o endoscópio rígido de zero graus ${ }^{\mathrm{g}}$. Após a inspeção da cavidade peritoneal, foi introduzido na região lateral direita, sob visibilização direta, outro trocarte de dimensão semelhante. O terceiro trocarte, de $5 \mathrm{~mm}$, foi posicionado na região lateral esquerda.

Realizou-se a apreensão do cólon descendente com pinça de Babcock ${ }^{\mathrm{h}}$ e o tracionamento do órgão até a parede abdominal lateral esquerda, a fim de se eleger o melhor local para a colopexia. Através da segunda cânula e com o auxílio de redutori, foi introduzido o marcador plástico previamente descrito. Na seqüência, utilizando-se porta-agulhas ${ }^{j}$ montado com lâmina de bisturi n⿳0 15 , realizou-se a escarificação das camadas serosa e muscular do cólon descendente, em sua superfície antimesentérica, de acordo com o tamanho do marcador. O peritônio e a fáscia transversa sofreram incisão de $2,5 \mathrm{~cm}$ paralelamente ao músculo reto abdominal. As lesões provocadas foram mantidas em contato com a pinça de Babcock. Para as suturas transparietais, realizouse a passagem de fio de polipropileno 3-0 montado em agulha 40x12 $\mathrm{mm}$ através do material de apoio e da pele. Sob visibilização direta, foi escolhido o local para a introdução da agulha na cavidade, sendo este posicionado lateralmente à ferida provocada na parede muscular, em seu aspecto caudal. Mantendo-se o cólon fixo com a Babcock, promoveu-se a introdução da agulha na sua superfície antimesentérica, na porção caudal da região escarificada, procurando-se não transpassar a camada mucosa do órgão. A extremidade agulhada do fio foi removida da cavidade medialmente à região incisada da parede abdominal e novamente transpassada através do material de apoio. Três outros pontos interrompidos simples foram aplicados de forma semelhante, mantendo-se todos reparados externamente com pinça de Kelly e distando aproximadamente $0,5 \mathrm{~cm}$ uns dos outros. Os pontos foram concluídos externamente à cavidade, por meio de nó de cirurgião sobreposto por dois meios-nós. Realizou-se a desinsuflação parcial do abdômen até a pressão de $5 \mathrm{mmHg}$, a fim de se verificar a ausência de hemorragia. Os trocartes foram removidos, e as feridas musculares ocasionadas pela introdução das cânulas maiores suturadas com náilon monofilamentar 2-0, em padrão de Sultan. As lesões cutâneas foram ocluídas com mesmo fio, em padrão interrompido simples.

No pós-operatório, os cães receberam ketoprofeno $\left(2 \mathrm{mg} \mathrm{kg}^{-1}\right)$ por via subcutânea, uma vez ao dia, por três dias, e tiveram suas feridas operatórias higienizadas diariamente com solução de iodo polivinil pirrolidona ${ }^{1}$ (PVP-I) a 1\%. As suturas cutâneas de ambos os grupos foram removidas em sete dias, enquanto as transparietais utilizadas na fixação do cólon foram retiradas ao final de dez dias.

Para a avaliação das colopexias, todos os cães foram submetidos à laparoscopia, sendo metade do número dos animais operada aos 14 dias de pósoperatório e o restante aos 28 dias. Nessas ocasiões, coletaram-se amostras para biópsias dos locais de fixação. Para tanto, foram utilizados três trocartes, sendo o primeiro introduzido na linha média ventral, pré-umbilical, por meio da técnica aberta, e os demais posicionados conforme previamente descrito. A amostra para biópsia foi coletada com o auxílio de pinça Maryland $^{\mathrm{m}}$ e tesoura de Metzenbaum ${ }^{\mathrm{n}}$.

Nas comparações entre os grupos, consideraram-se o tempo cirúrgico total, o tempo necessário para a realização de colopexia, as complicações transoperatórias, a manutenção das aderências do cólon, a ocorrência de aderências intraabdominais e os achados do exame histológico. As presenças de bactérias, células inflamatórias, tecido conjuntivo no local de aderência cirúrgica, infiltração desse tecido na musculatura esquelética e a vascularização foram classificadas de $0 \mathrm{a}+++$ a partir das colorações com hematoxilina-eosina e tricrômico de Masson. $\mathrm{Na}$ escala classificatória, 0 correspondeu a ausência da característica, + a pequena quantidade, ++ a moderada e +++ a grande quantidade. Os tempos foram analisados a partir do teste $\mathrm{T}$ de Student, sendo as diferenças consideradas significativas quando $p \leq 0,05$. No GL, os diferentes subgrupos foram avaliados quanto à viabilidade da técnica e à ocorrência de lesões no local de contato com o material de apoio para as suturas transparietais.

\section{RESULTADOS}

Foi possível realizar a colopexia em todos os animais em tempo médio de 28,00+3,62min e $35,94 \pm 9,35 \mathrm{~min}$ nos grupos A e L, respectivamente. A fixação do cólon propriamente dita foi obtida em $5,62 \pm 0,52 \mathrm{~min}(\mathrm{GA})$ e $10,44 \pm 5,37 \mathrm{~min}(\mathrm{GL})$. Os tempos totais dos procedimentos e das suturas de fixação do órgão foram significativamente maiores no GL $(p=0,02)$.

O número de cânulas, as disposições destas, e os instrumentais cirúrgicos utilizados se mostraram apropriados para a realização da técnica auxiliada por laparoscopia. No GL, observou-se a punção de baço com a agulha de Veress em um cão do subgrupo $S$ e a perfuração desse mesmo órgão com a extremidadê da cânula posicionada na linha média ventral em canino 
do $\mathrm{S}_{3}$. Em ambos os casos, a hemorragia proveniente das lesões apresentou resolução espontânea. Em $87,5 \%$ das cirurgias, o pneumoperitônio foi estabelecido a partir de única punção e, em dois cães, um de cada subgrupo supracitado, foram necessárias uma ou duas punções adicionais. Em um cão do S , ocorreu a penetração da agulha através da mucosa durante a aplicação do ponto transparietal, sem a ocorrência de extravasamento de conteúdo fecal. A agulha foi prontamente removida e, após a desinfecção de sua extremidade com PVP-I a $10 \%$, foi reposicionada. Ainda em animal do $\mathrm{S}_{4}$ ocorreu hemorragia proveniente da artéria epigástrica superficial caudal durante a passagem do ponto transparietal, sendo tal complicação adequadamente manejada com ligadura cruzada, abrangendo o vaso hemorrágico e a musculatura da parede abdominal. Já no GA, não foram constatadas complicações transoperatórias.

Durante os acompanhamentos pósoperatórios e por ocasião das biópsias laparoscópicas, não foram constatados sinais de peritonite em nenhum dos animais. Esses procedimentos duraram em média $25,95 \pm 4,85 \mathrm{~min}$, sendo a coleta do material propriamente dita realizada em $7,75 \pm 2,45 \mathrm{~min}$. A única complicação transoperatória ocorrida foi a punção do baço com a extremidade do primeiro trocarte em um cão do GL-S , não sendo necessário nenhum tipo de intervenção para a obtenção da hemostasia.

Nos animais do GA, a cicatrização das feridas operatórias ocorreu por primeira intenção. Em todos os cães do GL, foram constatadas lesões cutâneas e/ou subcutâneas nos locais de contato com os materiais para apoio das suturas. Nos representantes do $\mathrm{S}_{1}$ e do $\mathrm{S}_{4}$, observaram-se dermatites e celulites, sendo que as alterações do primeiro subgrupo foram mais graves, uma vez que o material de apoio alojouse no tecido subcutâneo. Nos cães do $S_{2}$ e do $S_{3}$, constataram-se dermatites superficiais nos locais de contato com os discos, sendo as lesões menos evidentes no terceiro subgrupo. Em todos os casos, as alterações responderam ao tratamento tópico com solução de PVP-I a 1\%, associado à remoção dos materiais.

Em 20 cães $(83,3 \%)$, o cólon se manteve firmemente fixado à parede abdominal. Dos quatro animais em que essa situação não estava presente, três pertenciam ao subgrupo $\mathrm{S}_{4}$ do GL e um ao GA. Nesses 20 cães, a condição mais comumente observada foi a aderência do omento ao sítio de colopexia, exceto em um representante de cada grupo. Todos os cães do GA apresentaram aderências do omento à linha média ventral. Um animal desse grupo possuía o epíploon fixado à parede abdominal lateral e ao ligamento largo, e esse último à região de colopexia. Outros dois animais desse grupo demonstraram aderência do omento à parede abdominal lateral. Já no GL, um representante do $S_{2}$ possuía o omento aderido à região de introdução do segundo trocarte, e outro, do subgrupo $\mathrm{S}_{4}$, apresentou fixação do ligamento falciforme ao local de sutura do cólon na parede abdominal.

O exame histológico realizado aos 14 dias demonstrou que os animais do GL apresentavam resposta mais acentuada em todos os parâmetros avaliados, principalmente os relacionados à deposição de tecido conjuntivo denso no local de aderência cirúrgica, e infiltração deste no músculo transverso abdominal. Em todos os animais, as fibras de colágeno apresentavam-se organizadas e de coloração esverdeada. Aos 28 dias, a reação inflamatória no GL regrediu, e a deposição de tecido conjuntivo no local de aderência cirúrgica e na musculatura esquelética se assemelhou entre os grupos. As fibras de colágeno também foram coradas de verde em todas as amostras. Nos dois períodos de avaliação, não se constatou a presença de bactérias, e as reações inflamatórias foram constituídas principalmente de células mononucleares. Os resultados das observações histológicas encontramse descritos na tabela 1 .

\section{DISCUSSÃO}

Das diferentes técnicas existentes para colopexia por celiotomia em cães, optou-se, para os animais do GA, pela incisional, apesar de FOSSUM et al. (2002) afirmarem que as não incisionais são igualmente eficazes. Tal escolha segue as ponderações de POPOVITCH et al. (1998), os quais teorizam que as incisionais podem estar associadas à fixação mais permanente do cólon. Considerando as observações de TROSTLE et al. (1998), os quais demonstraram que a aplicação de suturas transabdominais foi efetiva na obtenção de colopexia permanente em eqüinos por cirurgia laparoscópica, no GL procurou-se desenvolver método transparietal com a finalidade de diminuir a quantidade de trocartes, o tempo operatório e as dificuldades inerentes à sutura intracorpórea (BRUN et al., 2000).

Em duas colopexias no GL, ocorreram lesões de baço a partir da introdução da agulha de Veress ou da primeira cânula. Tais complicações são relatadas em cirurgias laparoscópicas de cães, sendo que geralmente as hemorragias resultantes apresentam resoluções espontâneas (HARDIE et al., 1996; POPE \& JONES, 1999), conforme o constatado no presente 
Tabela 1 - Resultados das avaliações histológicas referentes à presença de células inflamatórias, vascularização na região de colopexia, deposição de tecido conjuntivo no local de aderência cirúrgica, e infiltração desse tecido na musculatura esquelética. Os dados foram classificados em cruzes e tabulados de acordo com o tempo de biópsia, grupos e subgrupos dos animais experimentais. Na escala classificatória,$+++\mathrm{e}+++$ corresponderam a pequena, moderada e grande quantidade da característica.

\begin{tabular}{|c|c|c|c|c|c|c|c|c|c|}
\hline \multirow[t]{2}{*}{ Tempo } & \multirow[t]{2}{*}{ Grupo/ subgrupo } & \multicolumn{2}{|c|}{ Células inflamatórias } & \multicolumn{2}{|c|}{ Vascularização } & \multicolumn{2}{|c|}{$\begin{array}{l}\text { Técido conj. na aderência } \\
\text { cirúrgica }\end{array}$} & \multicolumn{2}{|c|}{$\begin{array}{l}\text { Infiltrado do tec. conj. na } \\
\text { musculatura }\end{array}$} \\
\hline & & GA & GL & GA & GL & GA & GL & GA & GL \\
\hline & GA / GLS1 & + & +++ & + & +++ & + & +++ & + & +++ \\
\hline & GA / GLS1 & + & ++ & + & +++ & + & +++ & + & +++ \\
\hline \multirow[t]{7}{*}{$14 d$} & GA / GLS2 & + & ++ & + & + & + & +++ & + & +++ \\
\hline & GA / GLS2 & + & ++ & ++ & + & + & +++ & + & +++ \\
\hline & - / GLS3* & - & + & - & + & - & + & - & + \\
\hline & - / GLS3 & - & + & - & ++ & - & ++ & - & ++ \\
\hline & GA / GLS1 & ++ & + & ++ & + & +++ & ++ & +++ & + \\
\hline & GA / GLS1 & ++ & + & ++ & + & +++ & +++ & +++ & +++ \\
\hline & GA / GLS2 & ++ & + & ++ & + & +++ & ++ & +++ & ++ \\
\hline \multirow[t]{4}{*}{$28 \mathrm{~d}$} & - / GLS2 & - & + & - & + & - & + & - & + \\
\hline & - / GLS3 & - & ++ & - & + & - & +++ & - & ++ \\
\hline & - / GLS3 & - & ++ & - & + & - & +++ & - & ++ \\
\hline & - / GLS4 & - & ++ & - & + & - & +++ & - & +++ \\
\hline
\end{tabular}

tecido conj. $=$ tecido conjuntivo.

infiltrado= infiltração.

* animal no qual a agulha teve contato com a mucosa, durante a aplicação da sutura transparietal.

trabalho. De outra forma, o não-reconhecimento do incorreto posicionamento da agulha no baço poderia ter ocasionado embolia fatal por ocasião da insuflação, como relataram GILROY \& ANSON (1987). Procurando minimizar a possibilidade de lesões durante a introdução da Veress, alguns autores indicam o seu posicionamento nas regiões hipogástrica (WILDT et al., 1977; GOMEZ, 2000) ou xifóide (GARGALLO et al., 1999); contudo, a segurança da punção parece estar mais relacionada ao treinamento e a familiaridade do cirurgião do que com o local propriamente dito (GUIMARÃES et al., 2001). O emprego de agentes anestésicos não barbitúricos poderia minimizar a chance de lesões esplênicas, visto os barbitúricos estarem associados à esplenomegalia (BAILEY \& PABLO, 1998).

TROSTLE et al. (1998) preconizaram a utilização de quatro trocartes para colopexias com sutura transabdominal em eqüinos. No presente trabalho, seguindo a sugestão de FREEMAN (1998), optou-se pelo emprego de três cânulas, com a finalidade de produzir menor lesão tecidual. O posicionamento das cânulas mostrou-se efetivo, apesar de diferir em relação a esses últimos autores que indicam como local de escolha o quadrante abdominal direito. Independentemente da localização exata dos trocartes, é necessário manter a disposição triangular entre estes (BROOKS, 1996), para que os instrumentos de trabalho possam ser manejados sem interferência. No grupo auxiliado por laparoscopia, foram realizadas escarificações nas superfícies do cólon e da parede abdominal, com o objetivo de promover a formação de aderências firmes e infiltradas na musculatura esquelética. Apesar de tal conduta ser defendida em colopexias convencionais (BURROWS \& ELLISON, 1992; FOSSUM et al., 2002), alguns autores acreditam que esse procedimento é desnecessário (ENGEN, 1986; MATTHIESEN \& MARRETTA, 1993). Em gastropexias, MACCOY et al. (1982) e FOX et al. (1988) afirmaram que, se as superfícies mesoteliais dos tecidos a serem aposicionados não forem removidas, existe a possibilidade de ocorrer fibrose incompleta. Considerando que, no GL, a sutura transparietal foi promovida com material de baixa reatividade tecidual (ELLISON, 1989) e removida ao final de dez dias, a 
simples aposição entre as superfícies mesoteliais poderia não ser suficiente para a manutenção da colopexia.

Em um animal do GL, a agulha do fio de sutura alcançou a luz do cólon durante a colopexia. Tal condição deve ser evitada para não ocorrer contaminação do local de fixação (BURROWS \& ELLISON, 1992; POPOVITCH et al., 1994; FOSSUM et al., 2002), o que pode ocasionar peritonite. A pronta remoção da agulha e desinfecção de sua extremidade evitaram a peritonite, conforme constatado a partir da avaliação laparoscópica 14 dias após e por meio do exame histológico (Tabela 1). No cão em que ocorreu a hemorragia proveniente da artéria epigástrica superficial caudal, a aplicação de ligadura em massa envolvendo o vaso lesado e a musculatura foi método efetivo para a hemostasia. Tal condição corrobora as observações de PEDROSA (1993) e KOLATA \& FREEMAN (1998), que sugerem técnica semelhante quando se torna necessário coibir hemorragias provenientes da parede abdominal no local de introdução dos trocartes.

Em todos os animais do GL, foram verificadas lesões cutâneas e/ou subcutâneas no local de contato com os materiais de apoio das suturas, sendo os casos mais graves constatados em $\mathrm{S}_{1}$ e os menos importantes em $\mathrm{S}_{3}$. Nos representantes do $\mathrm{S}_{1}$, as lesões possivelmente ocorreram devido à menor superfície de contato do cápton com a pele, associada à dureza do material testado e aos movimentos do cólon no decorrer do pós-operatório. Já nos do $\mathrm{S}_{3}$, possivelmente o disco de borracha possibilitou melhor distribuição das forças compressivas originárias da sutura e, por conseqüência, menor lesão tecidual.

Considerando que a laparoscopia tem se mostrado efetiva na avaliação das aderências produzidas em gastropexias (POPE \& JONES, 1999) e que as biópsias tomadas por esse método permitem ao cirurgião visibilizar a área enferma e obter amostras apropriadas de tecido, além de possibilitar a realização de múltiplas coletas e o controle seguro da hemostasia (SACKIER, 1992), no presente estudo, optou-se por sua utilização como ferramenta de comparação entre as técnicas.

Apesar de FILMAR et al. (1987) não constatarem diferenças significativas em relação à formação de aderências em ratos submetidos a lesões uterinas pelos acessos laparoscópico e convencional, outros autores afirmaram que a laparoscopia tem sido empregada com o objetivo de minimizar tal condição (SEKIBA et al., 1992). No presente estudo, observouse maior número de aderências do omento em outros locais além dos da colopexia nos animais do GA, em especial na linha média ventral. Isso pode ter ocorrido devido à maior lesão da superfície serosa pelo acesso, associada ao maior ressecamento dessa camada pela exposição ao ambiente externo, visto ambas as situações predisporem à formação de aderências (CROWE \& BJORLING, 1993).

Diferentemente de POPOVITCH et al. (1994), no presente estudo um dos animais do GA não manteve a colopexia durante o período pósoperatório. Já no GL, foram três os que não mantiveram, todos pertencentes ao $\mathrm{S}_{4}$. No representante do GA, acredita-se que a sutura provavelmente não abrangeu adequadamente a camada submucosa, o que, associado ao peristaltismo pós-operatório, não permitiu a manutenção da fixação, pois não foram constatados indícios de contaminação na musculatura e na cavidade abdominal por ocasião da laparoscopia. Tal camada é responsável pela maior resistência do órgão (ELLISON, 1989; MAST, 1997). Nos cães do GL, atribui-se a não-manutenção da colopexia à memória da placa de silicone, pois esta foi confeccionada a partir de tubo com grande elasticidade. Supõe-se, assim, que a sutura tenha promovido a ruptura das camadas do cólon devido à tração externa da placa associada ao peristaltismo intestinal, pois também não foram observados sinais de contaminação no exame laparoscópico.

A maior deposição de tecido conjuntivo denso no local de aderência cirúrgica e na musculatura esquelética aos 14 dias nos animais do GL pode estar relacionada à superior reação inflamatória local, conforme descreveram LEVINE \& CAYWOOD (1983) em gastropexias. Acredita-se que essa condição possa ter ocorrido devido a desvitalização tecidual nas superfícies justapostas, uma vez que a reação constituiu-se principalmente de células mononucleares, não sendo constatadas bactérias ou observados sinais de infecção nos locais de aderência cirúrgica. Está demonstrado o prolongamento da fase inflamatória das reparações das feridas na presença de tecido desvitalizado (POPE, 1996). Provavelmente, a maior lesão tecidual tenha acontecido graças à compressão excessiva entre as superfícies do cólon e do músculo transverso após a aplicação das suturas transparietais, pois, no método auxiliado por laparoscopia, o controle da tração do fio é menos preciso.

A elevada deposição de tecido conjuntivo nos cães do GL aos 14 dias, sem a presença de infecção, pode ser considerada como resultado positivo, já que a força da aderência está diretamente relacionada com a produção de colágeno local (IRVIN 
\& HUNT, 1974; ELLISON, 1989). O decréscimo da quantidade desse tecido aos 28 dias nos cães do GL pode ser explicado pela organização das fibras de colágeno com orientação não funcional, a qual ocorre na fase de maturação das feridas (JOHNSTON, 1990). A coloração verde das fibras em todos os animais demonstra a maturação das fibras de colágeno, e sugere a adequabilidade das aderências cirúrgicas, uma vez que anteriormente a essa etapa, na fase proliferativa, os valores de resistência à tração das feridas já são satisfatórios (ELLISON, 1989).

\section{CONCLUSÕES}

Conclui-se que a cirurgia auxiliada por laparoscopia proposta é adequada para a fixação do colon ao músculo transverso abdominal em cães; contudo, não está indicada como alternativa à colopexia incisional por celiotomia, haja vista a ocorrência de lesões teciduais nos locais de contato com os materiais de apoio para a sutura.

\section{FONTES DE AQUISIÇÃO}

${ }^{a}$ Cloreto de sódio, Texon, Viamão, RS; ' Silastic, D'altomare, Santo Amaro, SP. ' Prolene 3-0, Ethicon-Johnson \& Jhonson, São José dos Campos, SP; ${ }^{d}$ Mononylon 2-0 Ethilon, Ethicon- Johnson \& Johnson, São José dos Campos, SP; ${ }^{\text {e Agulha }}$ de Veress, Karl Storz, Rio de Janeiro, RJ; f Trocater/bainha $10 \mathrm{~mm}$, Edlo, Canoas, RS; ${ }^{\mathrm{g}}$ Endoscópio Hoopkins Karl Storz 10mm, Rio de Janeiro, RJ; ${ }^{\text {h }}$ Endo Babcock, Autosuture, Somerville, N.J; ${ }^{i}$ Redutor tipo diafrágma, Edlo, Canoas, RS; ${ }^{j}$ Porta agulhas curvo, Edlo, Canoas, RS; ${ }^{1}$ Riodine tópico, Rioquimica, São José do Rio Preto, SP; ${ }^{\mathrm{m}}$ Pinça Maryland curva, Edlo, Canoas, RS; ${ }^{\mathrm{n}}$ Tesoura de Metzenbaun curva, Edlo, Canoas, RS.

\section{REFERÊNCIAS BIBLIOGRÁFICAS}

BAILEY, J.E.; PABLO, L.S. Anesthetic and physiologic considerations for veterinary endosurgery. In: FREEMAN, L.J. Veterinary endosurgery. St. Louis : Mosby, 1998. Cap.2, p.2443.

BERMAN, I.R. Sutureless laparoscopic rectopexy for procedentia: technique and implications. Diseases of the Colon \& Rectum, v.35, n.7, p.689-693, 1992.

BROOKS, D.C. et al. Technique of open laparoscopy. In: Principles of endosurgery. Cambridge : Backwell Science, 1996. Cap.7, p.81-88.

BRUN, M.V. et al. Colopexia laparoscópica em cães - nota prévia. Ciência Animal Brasileira, v.1, supl., p.180, 2000.

BURROWS, C.F.; ELLISON, G.V. Moléstias anorretais. In: ETTINGER, S.J. Tratado de medicina interna veterinária. 3.ed. São Paulo : Manole, 1992. V.3. Cap. 92, p.1632-1648.

CROWE, D.T.; BJORLING, D.E. Peritoneum and peritoneal cavity. In: SLATTER, D. Textbook of small animal surgery. 2.ed. Philadelphia : Saunders, 1993. p.407-430.

ELLISON, G.W. Wound healing in the gastrointestinal tract. Seminars in Veterinary Medicine and Surgery (Small Animal), v.4, n.4, p.287-293, 1989.

ENGEN, M.H. Conduta no prolapso retal. In: BOJRAB, M.J. Cirurgia dos pequenos animais. 2.ed. São Paulo : Rocca, 1986. Cap.13, p.200-204.

FILMAR, S. et al. Operative laparoscopy versus open abdominal surgery: a comparative study on postoperative adhesion formation in the rat model. Fertility and Sterility, v.48, n.3, p.486-489, 1987.

FOSSUM, T.H. et al. Cirurgia do sistema digestório. In: Cirurgia de pequenos animais. São Paulo : Roca, 2002. $\overline{\text { Cap.16, }}$, p.222-405.

FOX, S.M. et al. Circuncostal gastropexy versus tube gastrostomy: histological comparison of gastropexy adhesions. Journal of the American Animal Hospital Association, v.24, p.273-279, 1988.

FREEMAN, L.J. Laparoscopic colorectal surgery. In: Veterinary endosurgery. St. Louis : Mosby, 1998. Cap. 8, p.144151.

GARGALLO, J.U. et al. Técnicas laparoscópicas en aparato genital de la hembra. Capturado em 27 jul. 1999. Online. Disponível na Internet http:www.aevedi.org/art1199.html.

GILROY, B.A.; ANSON, L.W. Fatal air embolism during anesthesia for laparoscopy in a dog. Journal of the American Veterinary Medical Association, v.190, n.5, p.552-554, 1987.

GOMEZ, H.M. Nefrectomia videolaparoscópica total direita em cães: estudo experimental. 2000. 83f. Tese (Doutorado em Cirurgia) - Faculdade de Medicina Veterinária e Zootecnia, Universidade de São Paulo.

GUIMARÃES, P. et al. Complicações em videolaparoscopia nas cirurgias experimentais. Capturado em 11 out. 2001. Online. Disponível na Internet http:www.cursosmedicos.com.Br/ teec03.html.

HARDIE, R.J. et al. Biomechanical and histological evaluation of a laparoscopic stapled gastropexy techinique in dogs. Veterinary Surgery, v.25, n.2, p.127-133, 1996.

IRVIN, T.T.; HUNT, T.K. Reappraisel of the healing process of anastomosis of the colon. Surgery, Gynecology \& Obstetrics, v.138, p.741-746, 1974.

JOHNSTON, D.E. Wound healing in skin. Veterinary Clinics of North America: Small Animal Practice, v.20, n.1, p.1-23, 1990.

KOLATA, R.J.; FREEMAN, L.J. Acess, port placement, and basic endosurgical skills. In: FREEMAN, L.J. Veterinary endosurgery. St. Louis : Mosby, 1998. Cap.3, p.44-60.

LEVINE, S.H.; CAYWOOD, D.D. Biomechanical evaluation of gastropexy techniques in the dog. Veterinary Surgery, v.12, n.3, p.166-169, 1983.

MACCOY, D.M. et al. A gastropexy technique for permanent fixation of the pyloric antrum. Journal of the American Animal Hospital Association, v.18, p.763-768, 1982. 
MAST, B.A. Cicatrização em outros tecidos. In: BARBUL, A. Cicatrização das feridas. Rio de Janeiro : Interlivros, 1997. p.529546.

MATTHIENSEN, D.T.; MARRETTA, S.M. Diaseases of the anus and rectum. In: SLATTER, D. Textbook of small animal surgery. 2.ed. Philadelphia : Saunders, 1993. p.627-645.

PEDROSA, F. Técnica de punção e pneumoperitônio na cirurgia vídeo-laparoscópica. In: CREUZ, O. Cirurgia video endoscópica. Rio de Janeiro : Revinter, 1993. Cap. 8, p.8396.

POPE, E.R. Cicatrização da pele. In: BOJRAB, M.J. Mecanismos da moléstia na cirurgia dos pequenos animais. 2.ed. São Paulo: Manole, 1996. Cap.24, p.178-183.

POPE, E.R.; JONES, B.D. Clinical evaluation of a modified circumcostal gastropexy in dogs. Journal of the American Veterinary Medical Association, v.215, n.7, p.952-955, 1999.

POPOVITCH, C.A. et al. Colopexy as a treatment for rectal prolapse in dogs and cats: a retrospective study of 14 cases. Veterinary Surgery, v.23, p.115-118, 1994.
SACKIER, J. Laparoscopia diagnóstica na doença não-malígna. In: MACFADYEN, B.V.; PONSKY, J.L. Clinicas cirúrgicas da América do Norte. Rio de Janeiro : Interlivros, 1992. p.1051-1060.

SEKIBA, K. et al. Use of interceed (TC7) absorbable adhesion barrier to reduce postoperative adhesion reformation in infertility and endometriosis surgery. Obstetrics \& Gynecology, v.79, n.4, p.518-522, 1992.

STEVENSON, A.R.L. et al. Laparoscopic-assisted resectionrectopexy for rectal prolapse: early and medium follow-up. Diseases of the Colon \& Rectum. v.41, n.1, p.46-54, 1998.

THOMPSON, S.E; HENDRICKSON, D.A. Hernia repair. In: FREEMAN, L.J. Veterinary endosurgery. St. Louis : Mosby, 1998. Cap.7, p.105-112

TROSTLE, S.S. et al. Laparoscopic colopexy in horses. Veterinary Surgery, v.27, p.56-63, 1998.

WELCH, G.H.; ANDERSON, J.R. Acute volvulus of the sigmoid colon. World Journal of Surgery, v.11, n.2, p.258-262, 1987.

WILDT, D.E.; KINNEY, G.M.; SEAGER, S.W.J. Laparoscopy for direct observation of internal organs of the domestic cat and dog. American Journal of Veterinary Research, v.38, n.9, p.14291432, 1977. 